\title{
ARTIGO
}

\section{Tempo, \\ cidade,}

\section{Sетма Rocha* educação.}

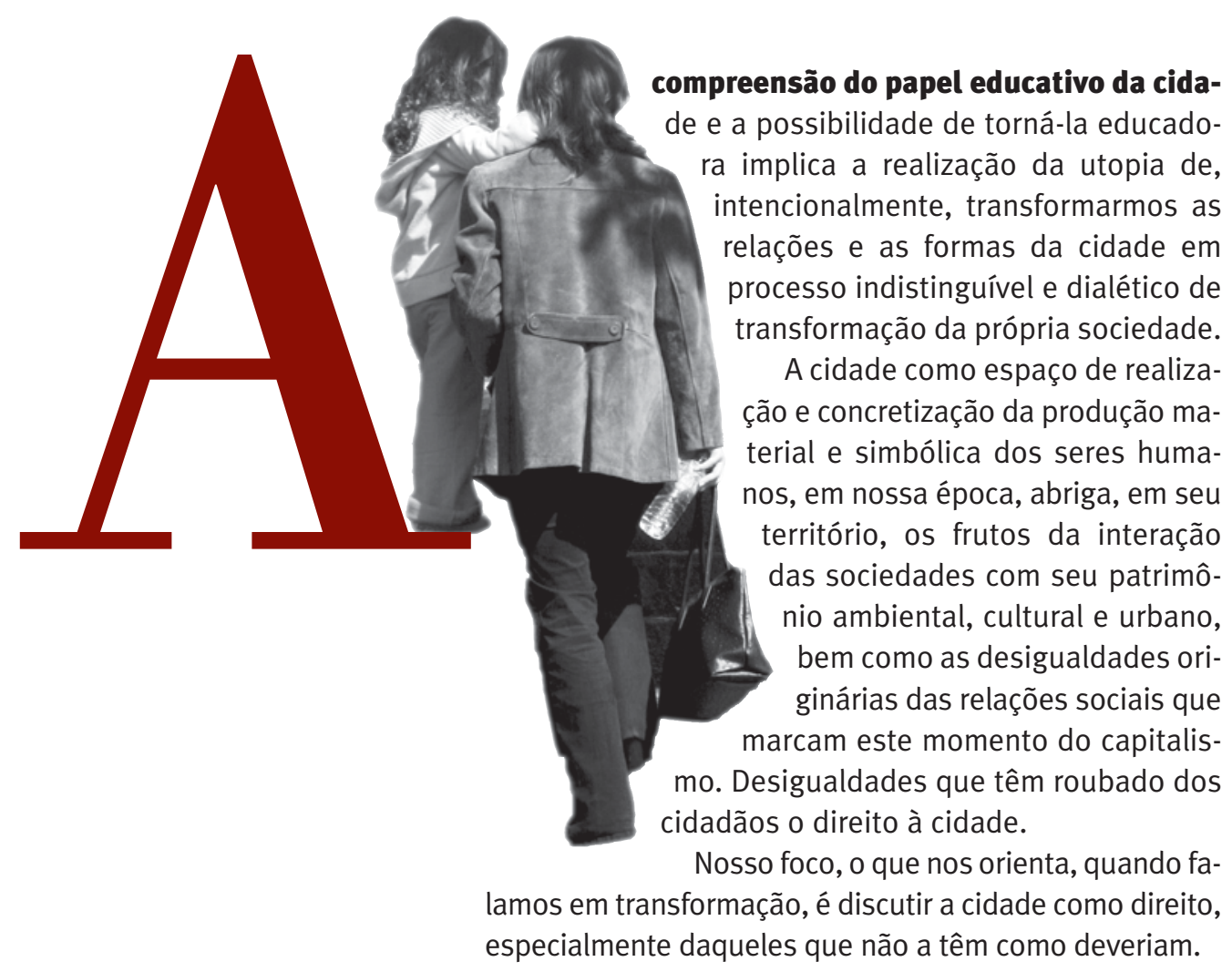

\section{Tempo e cidade}

Essa perspectiva, aparentemente óbvia, implica, entretanto, lançarmos nosso olhar para um horizonte mais amplo que o do atendimento às necessidades materiais imediatas - o que já se constitui, per si, em tarefa extremamente complexa e complicada em um país historicamente dependente como o nosso - um horizonte que possa contribuir para que desvelemos o movimento de

\footnotetext{
* Selma Rocha é historiadora; foi secretária de Educação da Prefeitura de Santo André e chefe de gabinete da Secretaria de Educação da Prefeitura de São Paulo.
} 
absolutização e homogeneização do tempo e, por conseguinte, das identidades e diferenças que se constituem num dos pilares de sustentação das desigualdades sociais.

Com efeito, a globalização econômica como potencialização do processo de concentração do capital, de extensão e intensidade nunca antes conhecidas pela humanidade, instaura uma lógica segundo a qual o tempo presente é o único tempo real, esvaziando ou instrumentalizando o passado e o futuro. É ao presente que os homens devem hipotecar o futuro e as energias.

A cidade passa, dessa forma, à condição de lugar onde o relevante é a sobrevivência, onde a fragmentação da percepção faz com que as relações e a paisagem urbana, apreendida pelo olhar, sejam guindadas à condição de espetáculo por meio de inúmeras formas de violência.

Esse contexto, identificado por muitos como pós-moderno - que impõe situações e imagens percebidas de maneira rápida e fugaz, como uma sucessão de fatos e situações, sem nexo e sentido - ao reproduzir-se, termina por subtrair a percepção do movimento da história.

"Esquecer o passado é negar toda efetiva experiência de vida; negar o futuro é abolir a possibilidade do novo a cada instante. Mais ainda, as idéias de justiça, liberdade, alteridade, pensamento tornam-se abstrações vazias no espaço e no tempo, a partir do momento em que qualquer ação já se sabe 'eternamente feita e absolutamente irreparável". ${ }^{1}$

A cidade pode constituir-se, pois, no lugar da morte da história. Se ousarmos, contudo, desconstruir a lógica que iguala o tempo à velocidade e o aprisiona nas tramas imperativas do mercado, teremos então a possibilidade de reconhecer e compreender outros tempos que são subordinados aos interesses que produzem, a cada dia, a desigualdade, a exclusão e a opressão de homens e continentes.

Tempos que, mesmo domesticados pelo capital, saltam por meio da memória e sobrevivem de maneira simultânea e recorrente nos cultos, nos mitos modernos e nas diversas experiências culturais que também definem o ser da cidade.

"As formações simbólicas (cantos, poemas, danças) e todas as manifestações litúrgicas desenrolam-se em um tempo existencialmente pleno. Mais rigorosamente: são essas formações que tornam o tempo existencialmente pleno."

É um tempo que a presença humana qualifica. É um tempo no qual a ação dos afetos e da imaginação produz

\section{Da caverna à cidade,}

$$
\begin{gathered}
\text { o homem foi instituindo } \\
\text { práticas e relações sociais } \\
\text { que permitiram } \\
\text { maior domínio sobre }
\end{gathered}
$$

o espaço e o tempo.

uma lógica própria, capaz de construções analógicas belamente ordenadas (...).

Se a economia procede mediante um jogo que alinha os mecanismos da produção, da oferta e da demanda, dispondo-os em séries, logo, medindo-os (pois o tempo vale produção que, por sua vez, vale dinheiro), isto não significa que esta lógica seja a única regra interativa que aproxime estavelmente os homens em sociedade". ${ }^{2}$

Tal constatação pode ser observada nas relações humanas que, ao formarem o ser humano, engendraram também o prenúncio das cidades.

\section{Cidade e tempo}

Assim, temos que os homens primitivos do paleolítico, antes mesmo de experimentarem a fixação em um território para gerar a produção de sua sobrevivência e superar a condição de coletores, já estabeleciam túmulos para o quais retornavam, "a fim de comungar com os espíritos ancestrais ou de aplacá-los". ${ }^{3}$

Também as cavernas se constituíram em lugar de retorno dos homens e mulheres para a manifestação artística e a realização de rituais.

"Nesses antigos santuários paleolíticos, como nos primeiros túmulos e montes sepulcrais, encontramos, se existem, os primeiros indícios de vida cívica, provavelmente muito antes de poder sequer suspeitar-se de qualquer agrupamento permanente em aldeias.(...) Ali, no centro cerimonial, verificava-se uma associação dedicada a uma vida abundante; não simplesmente um aumento de alimentos, mas um aumento do prazer social, graças a uma utilização mais completa da fantasia simbolizada e da arte com uma visão comum de uma vida melhor e mais significativa, ao mesmo tempo em que esteticamente atraente (...) Com efeito, quem pode duvidar de que no próprio esforço de assegurar um suprimento abundante de alimento animal - se era essa 
realmente a finalidade mágica da pintura e do rito - , a própria representação da arte acrescentou algo tão essencial à vida humana quanto as recompensas carnais da caça. Tudo isso tem a ver com a natureza da cidade histórica." 4

O lugar da cerimônia constitui-se, dessa forma, no espaço de interação entre passado e futuro, de encontro entre a vida e a morte, tão necessários à sobrevivência quanto a água e o alimento.

Da caverna, como espaço de proteção física e espiritual, ao acampamento; da aldeia, onde o homem transforma a natureza por meio de instrumentos e constrói santuários, às cidades com seus templos, mercados e fortificações; o homem foi instituindo um corpo de práticas e relações sociais que permitiram maior domínio sobre o espaço e o tempo, por meio dos transportes e da comunicação; o desenvolvimento da técnica e a ampliação da produção agrícola; a sofisticação dos meios de troca; o surgimento de formas específicas de apropriação da produção, de organização da sociedade e configuração do poder do homem sobre o homem, seja por meio do controle do Estado ou da guerra.

À medida que as sociedades se configuravam, as antigas cidades do Egito e da Mesopotâmia construíam representações de si mesmas e explicações sobre o mundo dos homens e dos deuses, como forma de perpetuar a civilização humana. A temporalidade, as crenças, as idéias, os valores e a expressão estética deixaram marcas inigualáveis nos monumentos e nos templos.

A cultura material e escrita deixada por essas civilizações, não obstante as extraordinárias dificuldades interpostas pelo tempo e pelos homens, não deixa de continuar inspirando as sociedades e desafiando o trabalho de arqueólogos e historiadores. Talvez, por isso, tenham eternizado a dimensão educativa de suas experiências.

Mas foi na Grécia que a dimensão educativa da cidade tomou a forma de intenção educadora. A pólis grega foi um espaço onde, intencionalmente, realizou-se a educação dos cidadãos.

As várias cidades-estado, por sua autonomia, tinham como condição de existência a liberdade - "liberdade coletiva”, como demonstrou Glotz. Liberdade exercida em nome de um passado comum que tecia os laços entre os membros da cidade.

"A terra sagrada da pátria é o recinto da família, os túmulos dos antepassados, os campos de que se conhecessem todos os proprietários, o monte aonde se vai cor- tar lenha, apascentar o rebanho ou recolher mel, os templos onde se assiste aos sacrifícios, a acrópole aonde se sobe em procissão; é tudo o que se ama, tudo o que é motivo de orgulho, tudo o que cada geração quer deixar mais sedutor do que quando o recebeu. Uma cidade, uma única cidade - algumas vezes ínfima -, e é por isso que Heitor corre para a morte, é por isso que o espartano considera o coroamento da 'virtude', 'tombar na primeira fila', é por isso que os combatentes de Salamina se lançam à abordagem ao som do peã e que Sócrates bebe a cicuta em respeito à lei". 5

Quando Atenas viveu o apogeu de sua vida política e cultural no século $V$ a.C., o exercício da liberdade e, portanto, da soberania, pressupunha a igualdade, como condição para esse seu exercício. ${ }^{6} \mathrm{~A}$ isonomia, igualdade perante a lei, e a isêgoria, direito igual de falar na Assembléia (Ekklesia), constituíram-se nos marcos de referência da democracia, principal instrumento de definição dos destinos da pólis. Apesar de o direito de cidadania ser limitado a poucos (mulheres, estrangeiros e escravos não eram cidadãos), a experiência democrática lançava sobre o futuro a perspectiva de solidariedade entre as gerações, à medida que faziam prosperar a cidade para os descendentes de antepassados comuns.

Por ser a lei soberana a que reina em companhia da razão, o logos, os destinos da democracia ateniense e, portanto, da pólis, foram objetos de intensa reflexão por parte dos pensadores gregos. A filosofia se debruçou sobre as contradições e insuficiências da democracia e, ao fazê-lo, homens como Platão ou Aristóteles, em diferentes momentos da história, contribuíram para que a busca da verdade estimulasse o compromisso dos cidadãos com a pólis, no âmbito das escolas filosóficas ou na Ágora.

Depois que o Império Romano do Ocidente desagregou-se e que a penetração dos chamados povos bárbaros se fez presente nos territórios de gregos e romanos, foi nos mosteiros que a pólis sobreviveu:

"O laço mais próximo entre a cidade clássica e a cidade medieval foi aquele então formado não pelos edifícios e costumes sobreviventes, mas pelo mosteiro. Foi no mosteiro que os livros da literatura clássica foram transferidos de papiros em decomposição para o resistente pergaminho; foi ali que a língua latina passou a ser falada na conversa diária e escapou um pouco à diversificação e mútua ininteligibilidade do italiano, do espanhol, do francês, do romeno, e de seus intocáveis dialetos regionais e variantes de aldeia; foi ali, pelo menos nas aba- 
dias beneditinas, que as práticas adiantadas da agricultura romana e da medicina grega foram conservadas, com uma correspondente elevação na produtividade e na saúde."7

0 desenvolvimento da cidade medieval, em muitos aspectos, superou a pólis no mundo ocidental. A maior parte de seus habitantes eram homens livres e, exceto em alguns casos, "morador da cidade e cidadão eram, agora, sinônimos". 8 Durante os dez séculos que configuraram a chamada Idade Média, a Igreja, ao dominar todos os aspectos da vida medieval, tornou a fé e o cristianismo o critério supremo de verdade. 0 trabalho de demonstração racional dessa verdade foi obra do conhecimento filosófico e da educação identificada com a persuasão.

Os processos de trabalho e produção (que, ao ligarem o homem à terra, tornaram-no livre), o temor e a necessidade de proteção, as obrigações servis e a educação para a fé cristã configuraram uma dimensão de tempo, uma noção de ordem, de regularidade, uma ética (em que a disciplina interior e a noção de caridade tiveram destaque) e estética das cidades que tiravam da natureza e dos céus sua maior inspiração.

O desenvolvimento do comércio e do capitalismo comercial - e todo o progresso técnico e científico que respondia às necessidades da economia e da burguesia nascentes - prepararam outras e novas cidades que, a partir da Revolução Francesa e da Revolução Industrial, começaram a abrigar relações e contradições muito próximas à experiência que nos é mais imediatamente familiar.

A racionalização dos processos produtivos - por meio de uma divisão social do trabalho que aparta, definitivamente, o artesão de seus meios de produção - a formação do proletariado, a quem só resta a venda da sua força de trabalho, e o advento de novos padrões de produção e consumo transformam a realidade das cidades européias.

O tempo da vida social e o tempo interno do indivíduo passam a ser ordenados pelo tempo e pela lógica do trabalho e da tecnologia. Na primeira metade do século XIX, "as atividades urbanas haviam perdido qualquer vínculo com o tempo da natureza; de há muito se encontram subordinadas ao tempo abstrato, ao dia implacavelmente dividido em 24 horas (...) o tempo abstrato e produtivo, o único capaz de constituir a sociedade disciplinada de ponta a ponta". 9

Em Londres e Paris, no século XIX, a classe operária passa a conformar a multidão de pobres explorados que, ao integrar e redefinir a paisagem urbana, reeduca o olhar e a percepção dos homens e da cidade. A vida cotidiana, como indica Stella Bresciani, assume a dimensão de um permanente espetáculo. Espetáculo que atemoriza. O olhar da burguesia e dos governantes, ao relacionar a pobreza ao vício e à degradação humana, teme, na Inglaterra, o contágio moral, e, na França, a ameaça política. Tal temor nada previa, contudo, da ameaça civilizatória que o desenvolvimento do capitalismo poderia representar, graças ao crescimento de extraordinárias forças produtivas e destrutivas.

Se o desenvolvimento do capitalismo, desde o final do século XIX, propiciou concentração de capital, poder e conhecimento tais que levaram a humanidade a duas guerras mundiais, capazes de destruírem cidades e suas populações, as lutas da classe operária, desde a segunda metade do século XIX, as revoluções nacionais e socialistas que marcaram o século XX e a experiência democrática contribuíram para que as cidades se tornassem espaços de profundos conflitos, mas também da conquista e afirmação de direitos sociais, civis e políticos.

\section{Cidade e educação}

Mas o que pode nos reservar o século XXI se, nas cidades, verificamos a cada dia a tensão entre fazer sobreviver nossos direitos e a tentativa de destruí-los; se constatamos que "além da exploração dos homens havia algo pior: a ausência de qualquer exploração - como deixar de dizer que, não sendo sequer exploráveis, nem sequer necessárias à exploração, ela própria inútil, as multidões podem tremer, e cada um dentro da multidão?". ${ }^{10}$

Como lutar, nas cidades, para que os homens não se tornem "supérfluos", quando as forças e os poderes que engendram as legiões de desempregados, miseráveis e abandonados em todo mundo parecem invisíveis às cidades e às próprias nações?

Como fazer sobreviver o ambiente natural e urbano, os monumentos, os prédios, os espaços públicos, os arquivos, a memória e a história, se vivemos sob a tirania do presente, do imediato, do fugaz e do veloz?

Ocorre que a "cidade tornou-se capaz de transmitir de geração a geração uma cultura complexa, pois pôde reunir não só os meios físicos, mas também os agentes humanos necessários para transmitir e aumentar essa herança. Este continua sendo o maior dos dons da cidade". ${ }^{11}$ 
As cidades - por deterem o potencial de registro da história dos homens e também por efetivamente a registrarem - denunciam os fracassos de nossa civilização, mas pelos diferentes níveis de experiência que agregam, pela diversidade cultural que abrigam, pelos tempos distintos com os quais convivem e, sobretudo, por suas próprias contradições pode, como possibilidade histórica, hospedar e promover movimentos de transformação que logrem conquistar e instituir mudanças estruturais mais profundas.

Dessa forma, a cidade pode se constituir no lugar onde os direitos se materializem na criação de espaços e relações que instaurem e oportunizem outros tempos: da luta e realização do trabalho, do lazer e da contemplação, da troca de experiências, da recriação de valores, da efetivação da solidariedade, da mobilização da memória, da reconstituição da história, da afirmação de identidades, da discussão democrática de problemas e alternativas.

É preciso, uma vez mais, evocar em nosso auxílio a experiência dos gregos - especialmente se considerarmos que, hoje, somos homens e mulheres livres, detentores, em tese, todos, de direitos de cidadania. Se o fazemos, é porque a reflexão e o diálogo públicos para decidir os destinos da pólis não nos parecem superados como experiência histórica pela democracia representativa. Ao contrário, eles podem e devem se aliar a ela.
Sublinhe-se, contudo, que a discussão sobre os rumos da cidade deve implicar mais que a discussão da ação imediata. É preciso tornar visíveis os processos e mecanismos que se encontram subjacentes às suas principais contradições.

Fundamentalmente, nisso reside a possibilidade educadora da cidade. Muito além de trazer benefícios pontuais às populações - registre-se outra vez: não secundários -, as experiências de participação devem permitir que os cidadãos vejam os cidadãos, que os cidadãos vejam a cidade, reconheçam seus problemas e compreendam sua história e as relações que a conformam. Referimo-nos à experiência de participação como processo de educação social e política que contribui para a auto-organização da sociedade, especialmente dos setores excluídos.

Para tanto, é imprescindível que as várias identidades presentes na vida urbana tenham, verdadeiramente, direito e espaço de expressão, manifestação, discussão e realização: as várias etnias, especialmente os negros; as várias classes, especialmente os pobres; os dois gêneros, especialmente as mulheres; as várias gerações, especialmente as crianças e os idosos; os portadores de deficiências, os homossexuais, pessoas de todos os credos e religiões.

É preciso que os interesses, necessidades e contra-

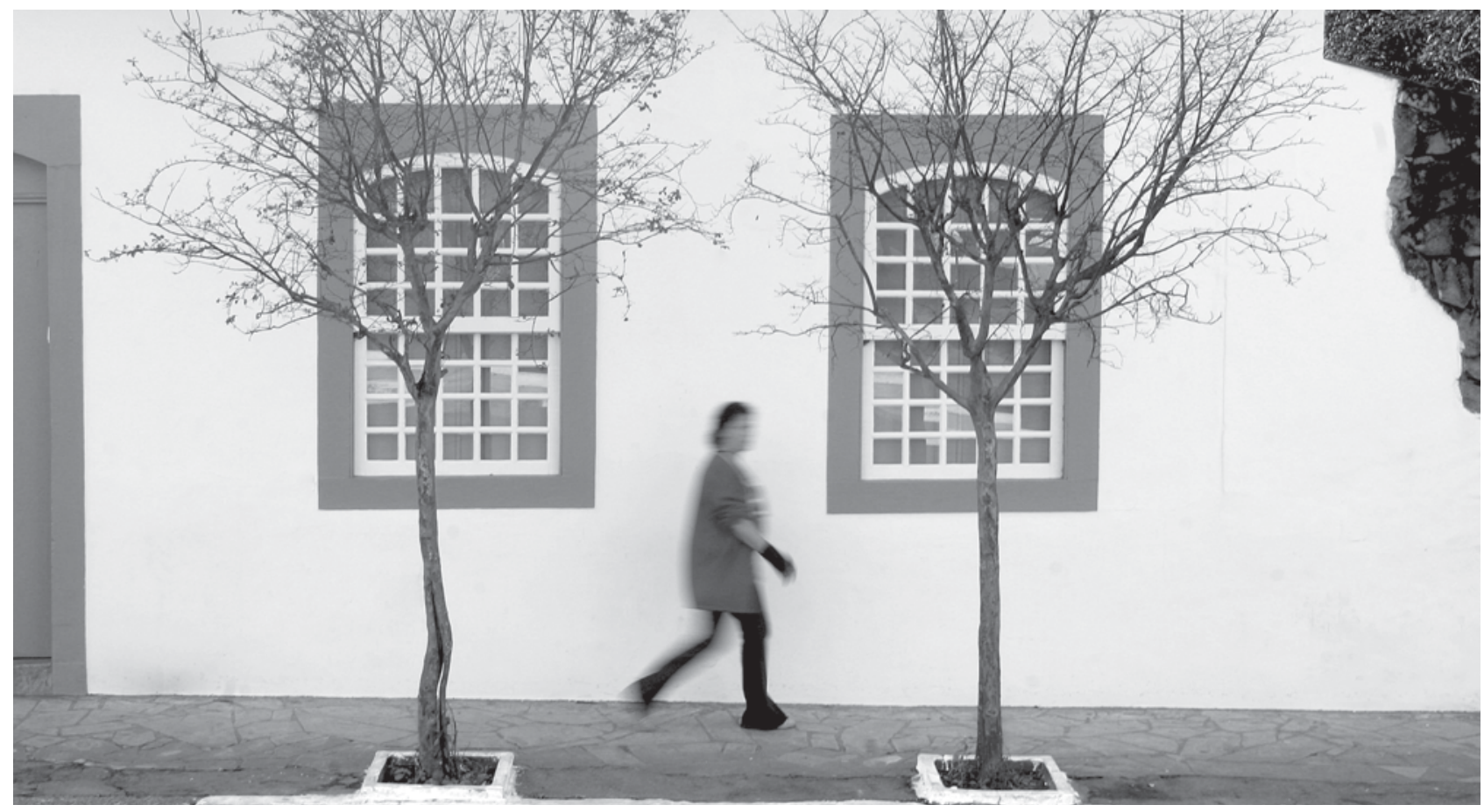




\title{
As cidades denunciam
}

\author{
os fracassos de nossa
}

civilização, mas podem

também promover

movimentos de

se a democracia nos inspirar como conduta política e como referência ética e, ainda, se não reduzirmos a ação política à mera estratégia de reprodução do poder, nos moldes da velha clientela.

Referimo-nos a espaços que permitam tornar a cidade deste novo século um lugar onde o debate sobre o desenvolvimento econômico não esteja apartado das principais questões relativas ao desenvolvimento humano e ecológico, e de tudo o que possa fazer sentido para a qualidade e realização do cidadão. Trata-se de estabelecer a negociação, propiciar o estabelecimento de compromissos e a adoção de propostas, seja pelos poderes públicos, seja pelos vários segmentos da sociedade.

Por outro lado, enfatizamos, a compreensão da cidade e dos cidadãos não poderá ser plena se não houver a valorização e a manifestação da memória como fenômeno social e individual. A memória liberta o tempo e o torna, como afirma Alfredo Bosi, "reversível".

"A memória articula-se formalmente e duradouramente na vida social mediante a linguagem. Pela memória, as pessoas que se ausentaram fazem-se presentes. Com o passar das gerações e das estações esse processo 'cai' no inconsciente lingüístico, reaflorando sempre que se faz uso da palavra que evoca e invoca. É a linguagem que permite conservar e reavivar a imagem que cada geração tem das anteriores. Memória e palavra, no fundo inseparáveis, são a condição de possibilidade do tempo reversível.

(...)

O diálogo com o passado torna-o presente. 0 pretérito passa a existir, de novo". ${ }^{12}$

Entretanto, a memória só se realiza por meio da comunicação na vida em sociedade.

Sem o domínio da linguagem, não há memória; se não há memória, não há história; se não há história, restanos o imperioso tempo e a lógica do mercado como os ordenadores da cidade e desfiguradores do humano.

Tudo isso nos remete aos processos formais, que se pretendem educadores, na cidade. Tudo isso nos remete à escola e ao papel da educação.

Desde logo, deixamos claro que a nossa preocupação fundamental não se resume à garantia de vagas nos vários níveis e modalidades de ensino, ainda que, óbvio, esse direito inalienável dos cidadãos seja fundamental ou, ainda, a garantia de condições materiais que favo-

reçam a permanência de alunos na escola. Isso porque entendemos que quantidade e qualidade da educação estão indissociavelmente ligadas.

Ao falarmos em memória e linguagem, tocamos naturalmente em uma das questões centrais para a cidade, para a nação e para a civilização: situarmos ou redefinirmos o papel social da educação.

De pronto, e sem temermos a simplificação, afirmamos que tal papel nada tem a ver com os processos de reprodução de informações e conhecimentos que remontam às necessidades do capitalismo desde a Revolução Industrial e que, de diferentes maneiras e formas, sobreviveram como paradigmas em várias partes do planeta, inclusive no Brasil.

As políticas de Estado - movidas que foram, de um lado, por outras prioridades econômicas que não a educação e, de outro, pelos supostos interesses do mercado - comumente, adotaram padrões de qualidade que, por seus supostos, visaram homogeneizar os conhecimentos dos educandos para atender objetivos nem sempre relativos ao seu desenvolvimento e emancipação cognitiva e intelectual.

Esse esforço de homogeneização tem envolvido a existência de currículos e processos de avaliação prédeterminados que - sem considerar a identidade de nossos alunos, suas experiências sociais e culturais, seus ritmos e tempos - estabelecem padrões que, quando não alcançados, levam à desqualificação e a se subestimarem as potencialidades. Às vitimas do chamado "fracasso escolar", resta a evasão ou as chamadas ações compensatórias que nada compensam, mas naturalizam o fracasso e ainda atribuem sua responsabilidade ao aluno ou à sua condição de pobreza.

Por todo o exposto, parece-nos necessário indicar que compete à educação, e à escola como instituição, construir conhecimentos e valores; criar e recriar a cultura e contribuir para que os alunos se percebam e se consti- 
tuam como sujeitos do processo educacional e da vida em sociedade. Isso implica desenvolver inúmeras capacidades. Percepção, identificação, comparação, representação, abstração, generalização e comunicação são algumas delas, entre outras necessárias, para que as gerações que passam pela escola possam exercitar a reflexão, a criatividade e a elaboração dos pensamentos e das idéias de forma livre, crítica e responsável.

Para tanto, em primeiríssimo lugar, é preciso tornar o educando o centro do trabalho educacional: investigando a sua identidade, compreendendo como apreende e representa a realidade, como se comunica, como se movimenta, como constrói sua cognição e sua afetividade. Tudo isso para que a escola possa identificar suas necessidades reais e ligá-las aos novos conhecimentos a serem explorados, em tantos campos quantos forem possíveis.

Ao concebermos tal papel para a educação, supomos uma pedagogia que, além de dialógica, seja capaz de lidar com as características e ritmos de cada um. Uma pedagogia que redefina os processos de construção e realização do currículo e da avaliação; contribua para que se desvelem as relações de poder que lhe são subjacentes e concorra para que a dúvida, a curiosidade epistemológica e a elaboração, nas escolas e espaços de gestão da política educacional, se tornem práticas sistemáticas e permanentes.

Essa perspectiva, sumariamente indicada, novamente nos remete à cidade.

Ao superar os mecanismos de pura reprodução, a escola pode lançar-se à incrível aventura de instigar o olhar e o pensamento; de promover o domínio da linguagem (ou das linguagens); de ensejar a criação, a comunicação e a expressão, e aproximar crianças, jovens e adultos da percepção e interação com o mundo e com os tempos que a cidade encerra. Homens que se educam na escola e na vida da cidade talvez ousem não se tornarem supérfluos.

A cidade pode também invadir a escola e os currículos. Contudo, não apenas para confirmar a pobreza material e cultural dos educandos, pois em muitos casos a compreensão da cidade e da vida das crianças no território tem função puramente instrumental: demonstrar o quanto lhes falta para ser.

A cidade pode entrar na sala de aula para ensinar matemática, química ou biologia; ecologia e geografia; respeito e cooperação. Ela pode entrar para mobilizar os conhecimentos de maneira multidisciplinar e mostrar o quanto as ciências, ao se desenvolverem, tornaram possível tanto uma melhor compreensão da realidade, quanto fragmentação da percepção - e, ainda, a defesa da vida e o desencadear da morte.

Entretanto, os cidadãos e a cidade podem também ser desvendados e descobertos no universo simbólico, cognitivo e afetivo de cada criança, jovem ou adulto por meio da educação. Talvez resida aí uma das primeiras possibilidades de realização do respeito na escola, na cidade; à cidade e aos cidadãos. No século XXI, talvez aí também se descubra o futuro da cidade.

\section{Referências bibliográficas}

1 NOVAES, Adauto. Sobre tempo e história. In: Tempo e história. São Paulo: Companhia das Letras, 1992, p. 9.

2 BOSI, Alfredo. 0 tempo e os tempos. In: Tempo e história. São Paulo: Companhia das Letras, 1992, p. 27.

3 MUNFORD, Lewis. A cidade na história. São Paulo: Martins Fontes, 2004, p. 13.

4 MUNFORD, Lewis, 2004, p. 16.

5 GLOTZ, Gustave. A cidade grega. São Paulo/Rio de Janeiro: Difel, 1980, p. 24 .

6 GLOTZ, Gustave, 1980, p. 108.

7 MUNFORD, Lewis, 2004, p. 271.

8 MUNFORD, Lewis, 2004, p. 344.

9 BRESCIANI, Maria Stella Martins. Londres e Paris no Século XIX: o espetáculo da pobreza. São Paulo: Brasiliense, 1982, p. 18.

10 FORRESTER, Viviane. O horror econômico. São Paulo: Fundação Editora da Unesp, 1997, p. 16.

11 MUMFORD, Lewis, 2004, p. 614.

12 BOSI, Alfredo, 1992, p. 29.

\section{Bibliografia}

BOSI, Alfredo. O Tempo e os tempos. In: Tempo e história. São Paulo: Companhia das Letras, 1992.

BRESCIANI, Maria Stella M. Londres e Paris no século XIX: o espetáculo da pobreza. São Paulo: Brasiliense, 1982.

FORRESTER, Viviane. O horror econômico. São Paulo: Fundação Editora da Unesp, 1997.

GLOTZ, Gustave. A cidade grega. São Paulo/Rio de Janeiro: Difel, 1980. MUMFORD, Lewis. A cidade na história. São Paulo: Martins Fontes, 2004. NOVAES, Adauto. Sobre tempo e história. In: Tempo e história. São Paulo: Companhia das Letras, 1992.

RYKWERT, Joseph. A sedução do lugar. São Paulo: Martins Fontes, 2004. SEVCENKO, Nicolau. Perfis urbanos terríveis em Edgar Allan Poe. Cultura e Cidades. Revista Brasileira de História, São Paulo, v. 5, n. 8/9, p. 69-83, set. 1984/abr. 1985. 